\title{
Efeitos de antimicrobianos e extratos vegetais sobre a microbiota intestinal e a freqüência de diarréia em leitões recém-desmamados ${ }^{1}$
}

\author{
Liliana Lotufo Oetting ${ }^{2}$, Carlos Eduardo Utiyama ${ }^{2}$, Pedro Agostinho Giani ${ }^{3}$, Urbano dos \\ Santos Ruiz ${ }^{3}$, Valdomiro Shigueru Miyada ${ }^{4}$
}

\author{
1 Pesquisa financiada pela FAPESP. \\ 2 Programa de Pós-graduação em Ciência Animal e Pastagens - Depto de Zootecnia, ESALQ/USP, CEP: 13418-900, Piracicaba/SP. \\ 3 Iniciação Cientifica, Dep. de Zootecnia da ESALQ/USP, Piracicaba/SP. \\ ${ }^{4}$ Depto. de Zootecnia, ESALQ/USP, CEP: 13418-900, Piracicaba/SP.
}

RESUMO - Foram realizados três experimentos envolvendo 120 leitões (21 aos 56 dias de idade) para avaliar os efeitos de antimicrobianos e extratos vegetais sobre a microbiota intestinal (experimento 1) e a freqüência de diarréia em leitões (experimentos 1, 2 e 3). Os animais foram distribuídos em pares (um macho castrado e uma fêmea) em 20 baias (unidade experimental), em um delineamento experimental de blocos casualizados, composto pelos tratamentos: controle - ração basal; antimicrobiano - ração basal com bacitracina de zinco, olaquindox e colistina (50 ppm de cada); extrato vegetal A, B e C ração basal com 700, 1.400 e $2.100 \mathrm{ppm}$ de extrato vegetal, respectivamente. O extrato vegetal continha óleo essencial de cravo, tomilho, orégano, eugenol e carvacrol. Ao final do experimento 1, foi sacrificado um animal por unidade experimental e coletadas amostras do raspado do intestino delgado para a análise microbiológica. Não foram encontradas diferenças na análise microbiológica. A frequência de diarréia dos animais que receberam antimicrobianos foi inferior à observada nos tratamentos controle e com extratos vegetais no período de 1 a 35 dias de experimentação. Portanto, apesar de não terem sido detectadas diferenças na microbiota, os antimicrobianos foram efetivos no controle da diarréia.

Palavras-chave: aditivos, extratos herbais, microbiologia, suínos

\section{Effects of antimicrobials and herbal extracts on intestinal microbiology and diarrhea incidence in weanling pigs}

\begin{abstract}
Two experiments with a total of 120 weanling pigs ( 21 to $56 \mathrm{~d}$ of age) were conducted to evaluate the effects of antimicrobials and herbal extracts on intestinal microbiota (experiment 1) and on fecal score (experiments 1, 2 and 3). Pigs were allotted in pairs (pens with a barrow and a female) to a randomized complete block design 12 replications of five treatments. Treatments consisted of: control - basal diet; antimicrobial - basal diet plus Zn bacitracin, olaquindox, and colistin (50 ppm of each); herbal extract A, B and C - basal diet plus 700 ppm, 1,400 ppm and 2,100 ppm of herbal extract, respectively. The herbal extract consisted of a mixture of essential oils of thyme, clove, oregano, eugenol and carvacrol. At the end of experiment 1, one animal of each experimental unit was slaughtered to collect samples of small intestine for microbiological analysis, that showed no significant difference. During 1-35 days of experiment, diarrhea incidence of pigs fed antimicrobials was lower than those fed control or herbal extract diet. Therefore, even though no statistical difference was observed in intestinal microbiota, antimicrobials were effective in diarrhea control.
\end{abstract}

Key Words: additives, herbal extract, microbiology, swine

\section{Introdução}

O período pós-desmama é uma fase extremamente complexa na vida do leitão. Leitões recém-desmamados possuem o trato digestório relativamente imaturo, o que leva à digestão ineficiente de carboidratos e proteínas, que resulta na passagem de substrato fermentável a outras porções do intestino delgado (Campabadal et al., 1995), propiciando um meio rico em substratos para bactérias patogênicas, que aumentam a incidência de diarréia pós-desmama.
Para auxiliar nessa fase, podem ser utilizados antimicrobianos promotores do crescimento, responsáveis por promover alterações na composição da microbiota intestinal. Entre essas alterações, incluem-se a perda da eficiência de fixação de certos microrganismos ao epitélio intestinal (Krause et al., 1997), a alteração no perfil e na quantidade de substâncias produzidas no lúmen intestinal (Jin et al., 1997) e o controle de bactérias causadoras de doenças não diagnosticáveis que reduzem o crescimento do animal (Menten, 2002). Apesar da comprovada capaci- 
dade de melhorar o desempenho de suínos, o uso de antimicrobianos como promotores de crescimento tem sido progressivamente restringido em diversos países, o que estimula a busca por alternativas como a utilização de extratos vegetais. Apesar de ainda não existir um consenso sobre a ação dos óleos essenciais, algumas hipóteses têm sido sugeridas, entre elas, o controle de patógenos pela atividade antimicrobiana, a atividade antioxidante, a melhora na digestão por meio do estímulo da atividade enzimática e da absorção de nitrogênio, além de outros efeitos relacionados a alterações na histologia do epitélio intestinal, à morfometria dos órgãos e ao controle da produção de amônia.

Embora os efeitos antimicrobianos de diversos extratos vegetais tenham sido comprovados em experimentos in vitro (Farag et al., 1989; Dorman \& Deans, 2000; Essawi \& Srour, 2000; Lambert et al., 2001; Kalemba \& Kunicka, 2003), seu mecanismo de ação ainda é pouco compreendido. De acordo com Dorman \& Deans (2000) e Lambert et al. (2001), o efeito antimicrobiano de um óleo essencial está relacionado, principalmente, à alteração da permeabilidade e da integridade da membrana celular bacteriana. Esse efeito foi comprovado em um estudo in vitro no qual o carvacrol e o timol (compostos fenólicos) atuaram sobre a integridade da parede celular de bactérias gram-negativas causando ruptura da membrana externa (Dorman \& Deans, 2000), todavia, ainda são necessários muitos estudos para comprovar este efeito in vivo.

Este trabalho foi realizado com o objetivo de avaliar o efeito da utilização de extratos vegetais sobre a microbiota intestinal e a frequiência de diarréia em leitões recém-desmamados.

\section{Material e Métodos}

O experimento foi realizado na ESALQ/USP, em Piracicaba/SP, utilizando-se 120 suínos híbridos no período dos 21 aos 56 dias de idade. A unidade experimental foi composta de uma baia com dois animais (um macho castrado e uma fêmea). Os tratamentos analisados foram: controle ração basal; antimicrobiano - ração basal com bacitracina de zinco, olaquindox e colistina (50 ppm de cada); extrato vegetal A, B e C-ração basal com 700, 1.400 e 2.100 ppm de extrato vegetal, respectivamente. O extrato vegetal foi composto de óleo essencial de cravo (com a adição de eugenol), tomilho e orégano (com a adição de carvacrol). Os extratos passaram por um processo de microencapsulamento com o objetivo de minimizar o sabor dos óleos na dieta e liberá-los, de forma controlada, no estômago do animal. A composição final do produto encapsulado consistiu de $20 \%$ da mistura dos óleos, sendo 3,33\% de óleo essencial de cravo, 3,33\% de eugenol (princípio ativo do cravo), 3,33\% de óleo essencial de orégano, $3,33 \%$ de carvacrol (princípio ativo do orégano) e $6,66 \%$ de óleo essencial de tomilho.

Durante o período experimental, foram utilizadas duas rações basais, uma pré-inicial ( 10 ao 140 dia de experimento) e outra inicial (15ㅇo ao $35 \underline{0}$ dia). As composições percentuais das rações basais, assim como os valores calculados de alguns nutrientes, encontram-se na Tabela 1.

No experimento 1, para análise da microbiota intestinal, foram utilizados 40 leitões híbridos com idade inicial e final de 21 e 56 dias, respectivamente, distribuídos em 20 baias (dois animais por baia) de acordo com o peso e o sexo. O

Tabela 1 - Composições centesimal e nutricional das dietas basais

Table 1 - Ingredient and calculated compositions of the basal diets

Ingrediente, \% Pré-inicial Inicial

Ingredient Pre-initial Initial

Milho(Corn)

Pre-initial Initial

Farelo de soja 46\%(Soybean meal 46\%)

$59,269 \quad 63,329$

Lactose

$6,000 \quad 2,992$

Plasma sangüíneo² (Plasma)

$4,300 \quad 2,000$

Fosfato bicálcico (Dicalcium phosphate) $\quad 1,227 \quad 1,497$

Calcário (Limestone)

$1,095 \quad 1,024$

Óleo de soja(Soybean oil)

$0,800 \quad 1,500$

L-lisina. $\mathrm{HCl} 78 \%$ (L-lysine)

$0,577 \quad 0,427$

L-treonina $98,5 \%$ (L-threonine)

$0,224 \quad 0,162$

DL-metionina $99 \%$ (DL-methionine)

$0,215 \quad 0,145$

L-triptofano $98 \%$ (L-tryptophan)

$0,081 \quad 0,016$

Cloreto de colina $60 \%$ (Choline chloride) $\quad 0,100 \quad 0,100$

Premix vitamínico (Vitamin premix) ${ }^{3} \quad 0,100 \quad 0,100$

Premix mineral (Mineral premix) ${ }^{4} \quad 0,100 \quad 0,100$

Sal (Salt)

$0,000 \quad 0,225$

Inerte e/ou promotor do crescimento $\quad 0,210 \quad 0,210$

Inert and/or growth promoter

Valor calculado, \%

Calculated value

$\mathrm{EM}(M E), \mathrm{kcal} / \mathrm{kg}$

$3.400 \quad 3.300$

Proteína bruta (Crude protein)

Lisina total (Total lysine)

20,00

19,50

Lisina digestível(Digestible lysine)

1,33

Treonina digestível (Digestible threonine)

1,50

1,19

Triptofano digestível (Digestible tryptophan)

Metionina digestível (Digestible methionine)

0,77

$0,27 \quad 0,21$

$0,46 \quad 0,39$

Metionina + cistina digestíveis

0,79

0,69

Digestible Met + Cys

Lactose

$11,76 \quad 4,00$

Cálcio (Calcium)

$0,85 \quad 0,87$

$\mathrm{P}$ disponível(Available $P$ )

$0,45 \quad 0,42$

Sódio (Sodium)

0,22

0,20

1 Produto comercial (commercial product): Nuklospray K-10.

2 Produto comercial (commercial product): AP920.

3 Quantidades supridas por $\mathrm{kg}$ de ração (Amounts per $\mathrm{kg}$ of diet): vit. A, $6.000 \mathrm{UI}$; vit. $\mathrm{D}_{3}, 1.500 \mathrm{UI}$; vit. E, $15 \mathrm{UI}$; vit. $\mathrm{K}_{3}, 1,5 \mathrm{mg}$; tiamina (thiamin), $1,35 \mathrm{mg}$; riboflavina (riboflavin), $4 \mathrm{mg}$; vit. piridoxina (pyridoxine), $2 \mathrm{mg}$; vit. $\mathrm{B}_{12}, 20 \mathrm{mg}$; ácido nicotínico (nicotinic acid), $20 \mathrm{mg}$; ácido fólico (folic acid), 0,6 mg; biotina (biotin), 0,8 mg; ácido pantotênico (pantothenic acid), $9,35 \mathrm{mg}$; Se, $0,3 \mathrm{mg}$

4 Quantidades supridas por kg de ração (Amounts per kg of diet): I, 1,5 mg; Co,

$1 \mathrm{mg} ; \mathrm{Cu}, 10$ o mg; Zn 100 mg; Fe, 100 mg; Mn, 40 mg. 
delineamento experimental utilizado foi o de blocos casualizados. Os animais foram alimentados à vontade durante todo o período experimental (35 dias). Ao final do experimento, foi sacrificado um animal por unidade experimental, coletando-se amostras do raspado do intestino delgado para a realização da análise microbiológica. As amostras foram mantidas sob refrigeração e, posteriormente, foram analisadas quanto à presença de microrganismos totais, gram-positivos totais, gram-negativos totais, bacilos totais, Streptococcus spp., E.coli, Staphylococcus sp., Campylobacter coli e Clostridium perfringens pelo método de plaqueamento, seguindo-se todas recomendações prescritas pelo laboratório.

Nos experimentos 1, 2 e 3, para determinação da freqüência de diarréia, foram utilizados 120 leitões híbridos dos 21 aos 56 dias de idade, distribuídos em 60 baias (dois animais por baia) de acordo com o sexo e o peso, totalizando 12 blocos (12 repetições por tratamento), em um delineamento em blocos casualizados. No entanto, como a creche experimental possuía apenas 20 baias, foram realizadas três repetições no tempo (quatro blocos por repetição no tempo). Os animais receberam água e ração à vontade durante todo período experimental. Para o cálculo da porcentagem de dias com ocorrência de diarréia nos períodos de 1 a 14 e 1 a 35 dias de experimentação, realizou-se diariamente a avaliação visual das fezes, conforme classificação de 1 a 4 ( 1 - fezes líquidas; 2 - fezes líquidas/pastosas; 3 - fezes pastosas e 4 - fezes sólidas), em que apenas os escores 1 e 2 indicaram a ocorrência de diarréia.

Os dados referentes à microbiologia intestinal foram transformados pela função $y=\log x$, em que $x$ é o número de unidades formadoras de colônias por grama de amostra do conteúdo intestinal (ufc/g). Os dados de freqüência de diarréia, em $\%$, foram transformados pela função $y=\operatorname{arcsen} \sqrt{(p / 100)}$, conforme recomendado por Barbin (2003). Posteriormente, foram submetidos aos testes de adequação ao modelo linear, à análise de variâncias (SAS, 2001) e à comparação de médias por contrastes de interesse.

\section{Resultados e Discussão}

Os resultados para Staphylococcus spp. foram menores que 10 Unidades Formadoras de Colônias (UFC) para todas amostras. Em relação ao Campylobacter coli, somente dois animais, pertencentes aos tratamentos Ea e Ec, apresentaram resultado positivo (100 UFC/g). Por isso, esses dados não constam na tabela com a descrição dos resultados das análises microbiológicas (Tabela 2).

Não houve diferença $(\mathrm{P}>0,05)$ entre os tratamentos para nenhum dos microrganismos analisados. Entretanto, é possível notar que o tratamento controle não apresentou contagem de microrganismos gram-negativos para nenhuma das quatro repetições, o que, provavelmente, foi ocasionado por falhas na metodologia de coleta e análise dos dados ou possíveis variações na microbiota intestinal.

A coleta das amostras foi realizada por meio da raspagem de todo o segmento do intestino delgado, sem diferenciar os segmentos do duodeno, jejuno e íleo. Entretanto, sabe-se que a composição bacteriana ao longo do intestino delgado pode apresentar grandes variações (Pedroso et al., 2005) e isso pode ter influenciado os resultados encontrados.

Um dos pré-requisitos para o estudo dos efeitos de certos componentes sobre a microbiota animal consiste na quantificação correta dos diferentes grupos de bactérias. O método de plaqueamento é o mais utilizado em estudos com animais. Entretanto, alguns autores têm questionado a eficácia dessa técnica na avaliação da composição, da estrutura e da estabilidade de um ecossistema intestinal, principalmente em decorrência de suas limitações fisiológicas, como meios de cultura seletivos, redução no número de bactérias durante o processo e ambiente

Tabela 2 - Médias das contagens de microrganismos (log UFC/g de conteúdo do intestino delgado) no intestino de leitões em função dos tratamentos

Table 2 - Average of microorganism counts (log units of colony/g of small intestine content) of weanling pigs according to treatments

\begin{tabular}{|c|c|c|c|c|c|c|c|}
\hline \multirow{2}{*}{$\begin{array}{l}\text { Microrganismo } \\
\text { Microorganism }\end{array}$} & \multicolumn{5}{|c|}{$\begin{array}{c}\text { Tratamento } \\
\text { Treatment }\end{array}$} & \multirow[t]{2}{*}{$\operatorname{Pr}>F$} & \multirow[t]{2}{*}{$\mathrm{CV}^{2}(\%)$} \\
\hline & $\mathrm{C}$ & A & $\mathrm{Ea}$ & $\mathrm{Eb}$ & Ec & & \\
\hline Totais & 6,151 & 7,581 & 6,631 & 6,431 & 6,800 & 0,56 & 18,22 \\
\hline Gram-positivos(gram-positive) & 6,151 & 7,526 & 6,610 & 6,238 & 6,756 & 0,57 & 18,74 \\
\hline Gram-negativos (gram-negative) & 0 & 3,248 & 0,636 & 4,888 & 2,898 & 0,14 & 118,81 \\
\hline Bacillus spp. & 1,448 & 3,484 & 2,374 & 5,908 & 2,898 & 0,30 & 89,66 \\
\hline Streptococcus spp. & 2,876 & 3,969 & 2,804 & 3,165 & 3,560 & 0,89 & 57,63 \\
\hline Escherichia coli & 3,729 & 5,210 & 3,942 & 4,255 & 3,853 & 0,43 & 28,13 \\
\hline Clostridium perfringens & 3,262 & 3,549 & 3,928 & 4,317 & 3,829 & 0,39 & 19,98 \\
\hline
\end{tabular}

${ }^{1} \mathrm{C}=$ controle (control); $\mathrm{A}=$ antimicrobiano (antimicrobial); Ea, Eb e Ec = 700, 1.400, 2.100 ppm de extrato vegetal (herbal extract), respectivamente.

${ }^{2}$ Coeficiente de variação (coefficient of variation). 
inadequado ao crescimento de todas as bactérias (Simpson et al., 1999).

A população microbiana apresenta constante modificação de seu equilíbrio natural. As variedades, as quantidades e a distribuição das bactérias no trato gastrintestinal são sensíveis a variações mínimas do estado fisiológico do animal (mudanças no pH, secreções enzimáticas, biliares, entre outras), a interações microbianas (tanto sinergismo quanto antagonismo) e à composição da dieta (Holzapfel et al., 1998). Portanto, qualquer tipo de alteração fisiológica e/ou estresse sofrido pelos animais também pode ter influenciado os resultados e alterar a composição da microbiota intestinal no momento da coleta das amostras.

O tratamento com antimicrobiano, em relação aos demais, apresentou os maiores valores numéricos para a maioria dos microrganismos analisados, o que pode ser um indicativo de que os antimicrobianos atuem na modificação da microbiota e não na redução do número de microrganismos. Alterações na microbiota intestinal foram confirmadas por Pedroso et al. (2005), que relataram que animais que receberam antimicrobianos apresentaram perfil diferenciado de bactérias no trato gastrintestinal em relação aos do tratamento controle. Outra hipótese é o fato de que a diarréia pode causar diminuição no número de genótipos bacterianos em diferentes segmentos do trato intestinal de suínos, o que, talvez explique a menor contagem de microrganismos no tratamento controle.

As porcentagens médias de ocorrência de diarréias, assim como as médias transformadas pela função $y=\operatorname{arcsen} \sqrt{(p / 100)}$ são apresentadas na Tabela 3 para os períodos de 1 a 14 e 1 a 35 dias de experimentação. A transformação dos dados foi necessária para efetuar a análise estatística.

A frequência de diarréia no período de 1 a 35 dias de experimentação diferiu $(\mathrm{P}<0,05)$ entre os tratamentos, sendo menor $(\mathrm{P}<0,05)$ nos animais que receberam antimicrobianos. Pelos valores numéricos, nota-se que os animais que receberam extratos vegetais na dieta apresentaram menor frequência de diarréia que aqueles do tratamento controle no período de 1 a 35 dias de experimentação.

A diarréia pós-desmame pode ser causada principalmente pela colonização da superfície epitelial por patógenos, como a Escherichia coli enterotoxigênica, a Salmonella typhimurium e o Clostridium spp. (Stewart \& Chesson, 1993), e pela presença de resíduos alimentares não digeridos e não absorvidos, que servem como substratos para os microrganismos patogênicos. Os resíduos de alimentos, juntamente com íons minerais (sódio, potássio e cloro) presentes no epitélio intestinal, contribuem para o aumento
Tabela 3 - Médias de frequência de diarréia (MFD, \%) e média transformada (MT) para os períodos de 1 a 14 e 1 a 35 dias de experimentação

Table 3 - $\quad$ Average diarrhea frequency (MFD, \%) and transformed average (MT) from 1-14 and 1-35 days of experimental period

\begin{tabular}{|c|c|c|c|c|}
\hline \multirow{3}{*}{$\begin{array}{l}\text { Tratamento } \\
\text { Treatment }\end{array}$} & \multicolumn{4}{|c|}{$\begin{array}{c}\text { Período } \\
\text { Period }\end{array}$} \\
\hline & \multicolumn{2}{|c|}{1 a 14 dias (days) } & \multicolumn{2}{|c|}{1 a $35 \operatorname{dias}(\text { days })^{2}$} \\
\hline & $\operatorname{MFD}(\%)$ & MT & $\operatorname{MFD}(\%)$ & MT \\
\hline $\mathrm{C}$ & 18,49 & 0,41 & 24,62 & 0,51 \\
\hline A & 11,82 & 0,31 & 10,56 & 0,30 \\
\hline $\mathrm{Ea}$ & 23,72 & 0,49 & 22,82 & 0,48 \\
\hline $\mathrm{Eb}$ & 14,80 & 0,36 & 18,89 & 0,41 \\
\hline Ec & 22,24 & 0,46 & 22,23 & 0,47 \\
\hline $\operatorname{Pr}>\mathrm{F}$ & - & 0,0902 & - & 0,0084 \\
\hline $\mathrm{CV}^{3}(\%)$ & - & 41,56 & - & 32,92 \\
\hline
\end{tabular}

${ }^{1} \mathrm{C}=$ controle (control); $\mathrm{A}=$ antimicrobiano (antimicrobial); $\mathrm{Ea}, \mathrm{Eb}$ e Ec $=700$, $1.400,2.100 \mathrm{ppm}$ de extrato vegetal (herbal extract), respectivamente.

2 Contrastes significativos: controle $\mathrm{x}$ antimicrobiano e antimicrobiano $\mathrm{x}$ Extratos.

2 Significantly different contrasts: control $x$ antimicrobial and antimicrobial $x$ herbal extract ${ }^{3}$ Coeficiente de variação (coefficient of variation).

da osmolaridade do conteúdo intestinal, dificultando o processo de reabsorção de água e desencadeando a diarréia (Etheridge et al., 1984; Nabuurs et al., 1993).

Os antimicrobianos podem atuar sobre o organismo animal por meio da redução da população microbiana, diminuindo a fermentação de carboidratos e a incidência de diarréia (Anderson et al., 1999). Embora as análises microbiológicas não tenham acusado redução da contagem de microrganismos para o tratamento antimicrobiano, a frequência de diarréia nos animais que receberam suplementação com antimicrobianos foi inferior à daqueles do tratamento controle em todos os períodos considerados. Portanto, pode-se afirmar que os antimicrobianos foram eficientes no controle da diarréia, mesmo não tendo apresentado redução no número de microrganismos analisados.

Um dos modos de ação atribuído aos extratos vegetais na dieta pode ser o efeito antimicrobiano. Em um estudo in vitro realizado por Dorman \& Deans (2000), os óleos essenciais de cravo, tomilho e orégano apresentaram pronunciado efeito antimicrobiano sobre os patógenos analisados. $\mathrm{O}$ efeito antimicrobiano está relacionado, principalmente, à alteração da permeabilidade e integridade da membrana celular bacteriana (Lambert et al., 2001). Existe uma relação entre a estrutura química dos compostos ativos presentes no extrato vegetal e seu efeito antimicrobiano (Farag et al., 1989) e, geralmente, esse efeito pode ser atribuído à presença de compostos fenólicos (Dorman \& Deans, 2000). Alguns extratos vegetais apresentam alto poder antimicrobiano sobre diversos patógenos em estudos in vitro. Esta também pode ser uma das explicações para 
que o tratamento com extratos vegetais tenha apresentado menores valores numéricos de freqüência de diarréia no período de 1 a 35 dias de experimentação em relação ao tratamento controle.

\section{Conclusões}

Os antimicrobianos e extratos vegetais analisados não apresentaram efeito significativo sobre a microbiota intestinal de leitões. A freqüência de diarréia dos animais que receberam antimicrobianos, no entanto, foi estatisticamente inferior à do tratamento controle ou com extratos vegetais no período de 1 a 35 dias de experimentação. Os extratos vegetais apresentaram resultados intermediários de frequência de diarréia entre o tratamento controle e com antimicrobianos.

Portanto, embora não tenham promovido diferenças significativas na microbiota intestinal, os antimicrobianos foram eficientes no controle da diarréia.

\section{Literatura citada}

ANDERSON, D.B.; McCRACKEN, V.J.; AMINOV, R.I. et al. Gut microbiology and growth-promoting antibiotics in swine. Pig News Information, v.20, p.115N-122N, 1999.

BARBIN, D. Planejamento e análise estatística de experimentos agropecuários. Arapongas: Midas, 2003. 194p.

BRUGALLI, I. Alimentação alternativa: a utilização de fitoterápicos ou nutracêuticos como moduladores da imunidade e desempenho animal. In: SIMPÓSIO SOBRE MANEJO E NUTRIÇÃO DE AVES E SUÍNOS, 2003, Campinas.Anais... Campinas: Colégio Brasileiro de Nutrição Animal, 2003. p.167.

CAMPABADAL, C.; VARGAS, E.; FONSECA, M. Evaluación de los ácidos orgánicos en la alimentación de lechones. I. Uso del ácido cítrico. Agronomía Costarricense, v.19, p.47-51, 1995.

DORMAN, H.J.D.; DEANS, S.G. Antimicrobial agents from plants: antibacterial activity of plant volatile oils. Journal of Applied Microbiology, v.88, p.308-316, 2000.

ESSAWI, T.; SROUR, M. Screening of some Palestinian medicinal plants for antibacterial activity. Journal of Ethnopharmacology, v.70, p.343-349, 2000.

ETHERIDGE, R.D.; SEERLEY, R.W.; WYATT, R.D. The effect of the diet on performance, digestibility, blood composition and intestinal microflora of weaned pigs. Journal of Animal Science, v.58, p.1396-1402, 1984.

FARAG, R.S.; DAW, Z.Y.; HEWEDI, F.M. et al. Antimicrobial activity of some egyptian spice essential oils. Journal of Food Protection, v.52, n.9, p.665-667, 1989.
HOLZAPFEL, W.H.; HABERER, P.; SNEL, J. et al. Overview of gut flora and probiotics. International Journal of Food Microbiology, v.41, n.2, p.85-101, 1998.

JIN, L.Z.; HO, Y.W.; ZHAO, X. Probiotics in poultry: modes of action. World's Poultry Science Journal, v.53, p.351$368,1997$.

KALEMBA, D.; KUNICKA, A. Antibacterial and antifungal properties of essential oils. Current Medicinal Chemistry, v.10, p.813-829, 2003.

KAMEL, C. A novel look at a classic approach of plant extracts. Feed Mix, p.19-24, 2000. Número especial.

KRAUSE, D.O.; WHITE, B.A.; MACKIE, R.I. Ribotyping of adherent Lactobacillus from weaning pigs: a basis for probiotic selection based on diet and gut compartment. Anaerobe, v.3, n.5, p.317-325, 1997.

LAMBERT, R.J.W.; SKANDAMIS, P.N.; COOTE, P.J. et al. A study of the minimum inhibitory concentration and mode of action of oregano essential oil, thymol and carvacrol. Journal of Applied Microbiology, v.91, p.453-462, 2001.

MELLOR, S. Herbs and spices promote health and growth. Pig Progress, v.16, n.4, p.18-21, 2000

MENTEN. J.F.M. Probióticos, prébióticos e aditiovos fitogênicos na nutrição de aves. In: SIMPÓSIO SOBRE INGREDIENTES NA ALIMENTAÇÃO ANIMAL, 2., 2002, Campinas. Anais... Campinas: Colégio Brasileiro de Nutrição Animal, 2002. p.251-276.

MILTEMBERG, G. Extratos herbais como substitutos de antimicrobianos na alimentação animal. In: SIMPÓSIO SOBRE ADITIVOS ALTERNATIVOS NA NUTRIÇÃO ANIMAL, 2000, Campinas. Anais... Campinas: Instituto Agronômico de Campinas, 2000. p.87-100.

NABUURS, M.J.A; ZIJDERVELD, F.G.; DE LEEUW, P.W. Villus height and crypt depth in weaned and unweaned pigs, reared under various circumstances in the Netherlands. Research in Veterinary Science, v.55, p.78-84, 1993.

PEDroso, A.A; OETTING, L.L.; UTIYAMA, C.E. et al. Variabilidade espacial da comunidade bacteriana intestinal de suínos suplementados com antibióticos ou extratos herbais. Revista Brasileira de Zootecnia, v.34, n.4, p.1225-1233, 2005.

STATISTICAL ANALYSIS SYSTEM - SAS. SAS user's guide: statistics. Cary: 1996. 955p.

SILVA, E.N. Antibióticos intestinais naturais: bacteriocinas. In: SIMPÓSIO SOBRE ADITIVOS ALTERNATIVOS NA NUTRIÇÃO ANIMAL, 2000, Campinas. Anais... Campinas: Instituto Agronômico de Campinas, 2000. p.15-24.

SIMPSON, J.M.; McCRACKEN, V.J; WHITE, B.A. et al. Application of denaturant gradient gel electrophoresis for the analysis of the porcine gastrointestinal microbiota. Journal of Microbiological Methods, v.36, p.167-179, 1999.

STEWART, C.S.; CHESSON, A. making sense of probiotics. Pig Veterinary Journal, v.31, p.11-33, 1993. 